\title{
Monoamine oxidase inhibition improves vascular function and reduces oxidative stress in rats with lipopolysaccharide-induced inflammation
}

\author{
Corina Rațiu ${ }^{1}$, Diana Uțu ${ }^{1}$, Alexandra Petruș², Pop Norbert ${ }^{3}$, Sorin Olariu³ ${ }^{3}$ Oana Duicu ${ }^{1,4}$, \\ Adrian Sturza $^{1,4}$ and Danina M. Muntean ${ }^{1,4}$ \\ ${ }^{1}$ Department of Pathophysiology - Functional Sciences, Faculty of Medicine, "Victor Babeș" University of Medicine and \\ Pharmacy, Timișoara, Romania \\ 2 Department of Anatomy, Physiology and Pathophysiology, Faculty of Pharmacy, "Victor Babeș" University of Medicine and \\ Pharmacy, Timişoara, Romania \\ ${ }^{3}$ First Department of Surgery, Faculty of Medicine, "Victor Babeș" University of Medicine and Pharmacy, Timișoara, Romania \\ ${ }^{4}$ Center for Translational Research and Systems Medicine, "Victor Babeș" University of Medicine and Pharmacy, Timișoara, \\ Romania
}

\begin{abstract}
Oxidative stress and vascular inflammation are the two major pathomechanisms that contribute to the progression of both cardiovascular and metabolic diseases. We have previously demonstrated that monoamine oxidases (MAOs), mitochondrial enzymes with two isoforms (A and B), are contributors to the endothelial dysfunction associated with inflammation in mice. The present study was purported to assess the effects of MAOs on endothelial dysfunction in rats with lipopolysaccharide (LPS)-induced acute inflammation. To this aim, aortas harvested from rats treated or not with a single dose of LPS were used for organ-bath studies of vascular reactivity and hydrogen peroxide $\left(\mathrm{H}_{2} \mathrm{O}_{2}\right)$ production assessment in the presence vs. absence of MAO inhibitors. Our results demonstrate that $\mathrm{MAO}-\mathrm{A}$ and $\mathrm{B}$ isoforms are induced in the rat vascular system after LPS administration. Both reversible and irreversible MAOs inhibition improved vascular function and reduced oxidative stress. In conclusion, MAOs are contributors to the occurrence of endothelial dysfunction in the rat model of LPS-induced acute inflammation. MAO inhibition may become a viable therapeutic strategy for the treatment of cardiometabolic disease.
\end{abstract}

Key words: Monoamine oxidase - Lipopolysaccharide - Acute inflammation — Endothelial dysfunction - Oxidative stress

\begin{abstract}
Abbreviations: CLORG, clorgyline; eNOS, endothelial nitric oxide synthase; FAD, flavin-adenosinedinucleotide; $\mathrm{H}_{2} \mathrm{O}_{2}$, hydrogen peroxide; LPS, lipopolysaccharide; MAOs, monoamine oxidases; MCB, moclobemide MAOIs, monoamine oxidase inhibitors; ROS, reactive oxygen species; SELEG, selegiline.
\end{abstract}

\section{Introduction}

Vascular oxidative stress and chronic inflammation have been recognized as the central pathomechanisms that contribute to the progression of the main cardiometabolic diseases of the century, namely arterial hypertension, obesity

Correspondence to: Adrian Sturza, Department of Pathophysiology - Functional Sciences, “Victor Babeș” University of Medicine and Pharmacy of Timișoara, 2, Eftimie Murgu Sq., 300041 Timișoara, Romania E-mail: sturza.adrian@umft.ro and diabetes mellitus. The early event of all these pathologies is represented by the endothelial dysfunction characterized by an impairment of the vascular redox state (Daiber and Munzel 2015; Galley and Straub 2017; Mozos and Luca 2017; Mozos and Stoian 2017).

Four classical sources of reactive oxygen species (ROS) have been systematically incriminated as contributors to the vascular oxidative stress: NADPH oxidases, mitochondrial electron transport chain, uncoupled endothelial nitric oxide synthase (eNOS), and xanthine oxidase (Brandes et al. 2010; Drose and Brandt 2012; Forstermann and Sessa 2012; 
Higgins et al. 2012; Muntean et al. 2016). In the past two decades, monoamine oxidases (MAOs) with 2 isoforms, MAO-A and $\mathrm{B}$, at the outer mitochondrial membrane, have emerged as novel sources of oxidative stress in the cardiovascular system in both animals and humans (reviewed in Kaludercic et al. 2014a; Duicu et al. 2015; Maggiorani et al. 2017).

MAOs are flavin-adenosine-dinucleotide (FAD) containing dehydrogenases that catalyze the degradation of neurotransmitters and biogenic amines with the constant generation of hydrogen peroxide as one of the deleterious by-products. MAO-mediated oxidative neuronal and non-neuronal injury in the brain is a widely acknowledged pathomechanism in Parkinson's and Alzheimer's diseases, depression and anxiety, and the therapeutic effects of a wide range of both reversible and irreversible MAO inhibitors have been extensively reported over the past 50 years (reviewed in Bortolato et al. 2008; Edmondson and Binda 2018; Tripathi et al. 2018). However, MAOs have a variable expression profile and a widespread tissue distribution in several organs such as: liver, intestine, lung, thyroid gland, kidney, heart, blood vessels, platelets (Grimsby et al. 1990). Under physiological conditions, adrenaline, noradrenaline and serotonin are the preferred substrates for MAO-A, and phenylethylamine, benzylamine for MAO-B, respectively, whereas dopamine, tyramine and triptamine are degraded by both isoforms. With respect to the pharmacological inhibition, MAO-A is selectively inhibited by clorgyline (irreversibly) and moclobemide (reversibly), whereas MAO-B activity is blocked by selegiline (irreversibly) and lazabemide (reversibly), irrespective of tissue and substrate differences (Youdim et al. 2006).

We have previously demonstrated that lipopolysaccharide (LPS) administration in mice elicited both MAO-A and $\mathrm{B}$ up-regulation in aortic rings with a significant increase in ROS production and subsequent endothelial dysfunction. Ex vivo treatment with MAO inhibitors were able to reduce the oxidative stress and improve the vascular reactivity, respectively (Sturza et al. 2013a).

In order to recapitulate the effects observed in mice, the aim of the present study was to assess the effects of both irreversible and reversible $\mathrm{MAO}$ inhibition on vascular function and ROS generation in the experimental model of LPS-induced inflammation in rats.

\section{Materials and Methods}

\section{Study design and animal procedures}

Wistar rats where purchased from the Cantacuzino Institute (Bucharest, Romania). The animals were housed under standard conditions (i.e. constant temperature and humidity of $22.5 \pm 2{ }^{\circ} \mathrm{C}$ and $55+5 \%$, with 12 hours light-dark cycle). At the age of 8 weeks, 12 hours before each experiment, a single dose of LPS ( $8 \mathrm{mg} / \mathrm{kg}$ ) was administered. All experimental procedures were performed in accordance with the Guide for the Care and Use of Laboratory Animals (published by the US National Institute of Health), the Directive 2010/63/ EU and the Romanian Law nr. 43/May 2014 concerning the protection of animals used for scientific purposes. The experimental protocol was submitted for approval by the Committee for Research Ethics of "Victor Babeș" University of Medicine and Pharmacy from Timișoara, Romania.

\section{Rat aorta isolation and preparation of vascular rings}

After deep general anesthesia was obtained, abdominal laparotomy followed by exposure of the thoracic cavity and sternotomy were performed. The inferior vena cava was sectioned superior to the liver, after which the right ventricle was punctured and infused with Hanks solution (HBSS, AppliChem). The aorta was harvested and maintained in Hanks solution on ice, carefully cleared from connective and adipose tissue, and sectioned into rings between $2-4 \mathrm{~mm}$. The aortic rings where mounted in the four myograph chambers, previously filled with Krebs-Henseleit buffer solution ( $\mathrm{NaCl} 149.2 \mathrm{mmol} / 1, \mathrm{KCl} 2.7 \mathrm{mmol} / \mathrm{l}, \mathrm{NaHCO}_{3} 11.9 \mathrm{mmol} / \mathrm{l}$, $\mathrm{CaCl}_{2} 1.8 \mathrm{mmol} / \mathrm{l}, \mathrm{MgCl}_{2} 0.5 \mathrm{mmol} / \mathrm{l}, \mathrm{NaH}_{2} \mathrm{PO}_{4} 0.4 \mathrm{mmol} / \mathrm{l}$, glucose $5.5 \mathrm{mmol} / \mathrm{l})$, heated at $37.1^{\circ} \mathrm{C}$ and oxygenated. Diclofenac $(10 \mu \mathrm{mol} / \mathrm{l})$ was added in Krebs solution in order to suppress prostaglandins' synthesis (cyclooxygenase inhibitor) and their influence on vascular reactivity.

\section{Organ bath studies}

After equilibration of the rings (60 minutes), all the rings were contracted twice with $\mathrm{KCl}$ solution $(80 \mathrm{mmol} / \mathrm{l})$ in order to test the vascular smooth muscle viability. Precontraction started with cumulative doses of Phenylephrine (Phe), from $10^{-8}$ to $10^{-5} \mathrm{mmol} / \mathrm{l}$, in order to achieve a contraction of approximately $80 \%$ of the contraction to $\mathrm{KCl} 80 \mathrm{ml}$. Once the rings have reached this level of contraction, acetylcholine (Ach) was added in cumulative doses, from $10^{-9}$ to $10^{-5} \mathrm{mmol} / \mathrm{l}$, in order to obtain the endothelial-dependent response. The experiments were performed in the presence (30 min incubation) or absence of MAO inhibitors - clorgyline (CLORG, $10 \mu \mathrm{mol} / \mathrm{l}$, irreversible MAO-A inhibitor) and selegiline (SELEG, $10 \mu \mathrm{mol} / \mathrm{l}$, irreversible MAO-B inhibitor). Since it has been reported that MAO-A is the predominant isoform in endothelial cells in the rat (Westlund et al. 1993) we have also investigated the effect of moclobemide (MCB, $10 \mu \mathrm{mol} / \mathrm{l})$, a reversible MAO-A inhibitor.

\section{Assessment of hydrogen peroxide generation}

Hydrogen peroxide production was evaluated in rat aortic rings, in both the presence and the absence of $\mathrm{MAO}$ 
inhibitors (clorgiline and selegiline), by using the Ferrous iron xylenol orange oxidation method (FOX Assay, PeroxiDetect Kit, Sigma Aldrich) and the Amplex Red/horse radish peroxide (HRP) oxidation (Invitrogen) as previously described (Sturza et al. 2013).

\section{Real time polymerase chain reaction (RT-PCR)}

Total RNA was isolated (“Total RNA Mini SI Isolation Spin-Kit) and used for reverse transcription (Superscript III RT, Invitrogen). Quantitative RT-PCR was performed in rat aortic rings treated with or without LPS. In order to determine MAO expression, primers against MAO isoforms were designed using sequence information from the NCBI database $\left(5^{\prime} \rightarrow 3^{\prime}\right)$ : rat MAO-A fw TCT CAG GAT TGG CTG CTG CCA AAC; rat MAO-A rev CAG GTG GAA ATG CAC CAC GGA ATG; rat MAO-B fw TGG GCC AAG AGA TTC CCA GTG ATG; rat MAO-B rev AGA GCG TGG CAA TCT GCT TTG TAG. The housekeeping gene (EEF2, eukaryotic elongation factor 2$)$ and its primers were as follow $\left(5^{\prime} \rightarrow 3^{\prime}\right)$ : EEF2 fw: GAC ATC ACC AAG GGT GTG CAG and EEF2 rv: GCG GTC AGC ACA CTG GCA TA.

\section{Statistics}

All values are presented as mean \pm SEM and were analyzed using one-way ANOVA test. Data analysis of the dose-effect response curves was performed using the ANOVA F-test (comparisons of bottom and top values, EC50 and the Hill slope). Values of $p<0.05$ were considered statistically significant.

\section{Results}

\section{LPS increased expression of both MAO isoforms in rat} aortic rings

In order to elucidate if MAO could be a mediator of endothelial dysfunction elicited of systemic inflammation we investigate the effect of LPS in vivo administration on MAO gene expression in rat aorta. Our results have showed the presence of both MAO isoforms in isolated rat aortic rings, with the predominance of the MAO-B isoform (Fig. 1A). Both isoforms are upregulated after the in vivo treatment with a single dose of LPS (Fig. 1B).

\section{Incubation with MAO inhibitors improved vascular func- tion in LPS-treated rats}

Since LPS was able to increase MAO aortic expression we thought to investigate whether MAO inhibition is able to modify the vascular reactivity. We harvested aortas from
LPS-treated rats and incubated them with MAO inhibitors (CLORG, SELEG, MCB, $10 \mu \mathrm{mol} / \mathrm{l}$ ) for 30 minutes. As shown by the organ bath studies, a significant increase in contractility to Phe, as well as a strong attenuation of the endothelium-dependent relaxation to Ach were achieved after LPS treatment. Incubation with MAO inhibitors partially restored both the vascular contractility and the relaxation response (Fig. 2, 3, 4).

Incubation with MAO inhibitors reduced oxidative stress in LPS-treated aortic rings

We further assessed the magnitude of oxidative stress in the setting of LPS-induced experimental inflammation. After LPS treatment, the basal level of ROS was significantly increased, as proven by both FOX and Amplex Red assays (Fig. 4). Also, incubation (30 minutes) of rat aortic rings with MAO inhibitors (CLORG, SELEG, MCB, $10 \mu \mathrm{mol} / \mathrm{l}$ )
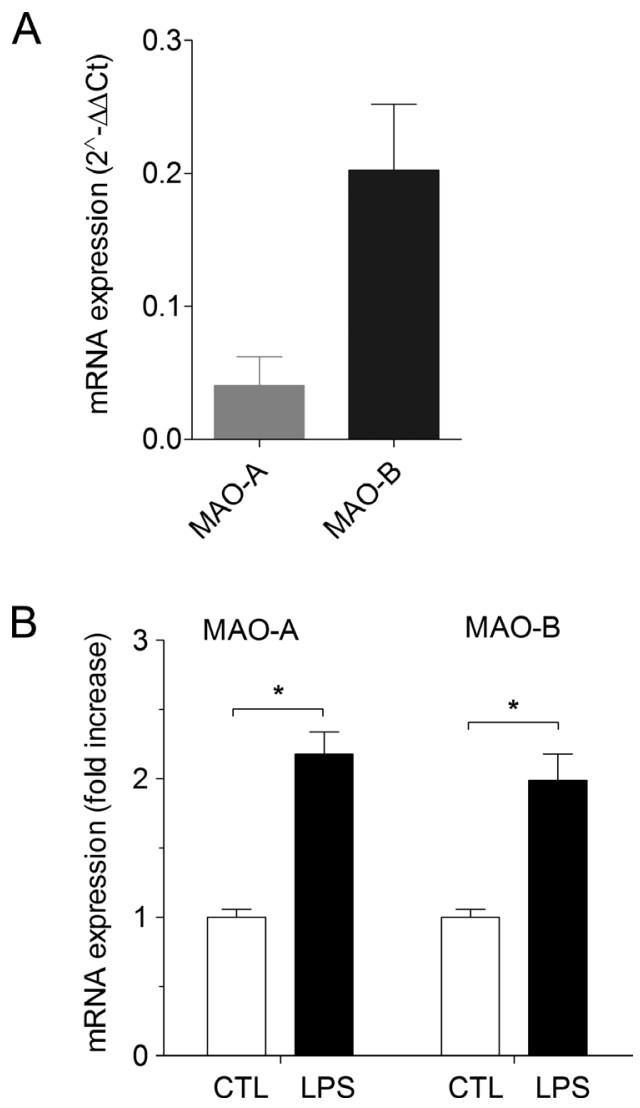

Figure 1. MAO mRNA expression in rat aortic rings. A. RT-PCR (mRNA expression: $2^{-\Delta \Delta C t}$ ) for MAO-A and MAO-B relative to the housekeeping gene EEF2 $\alpha$ in rat aortic rings. B. RT-PCR (fold increase) for MAO-A and MAO-B relative to the housekeeping gene EEF $2 \alpha$ in rat aortic rings after treatment with LPS. $n=6$, ${ }^{\star} p<0.05$ CTL $v s$. LPS. MAO, monoamine oxidase; CTL, control; LPS, lipopolysaccharide. 
A

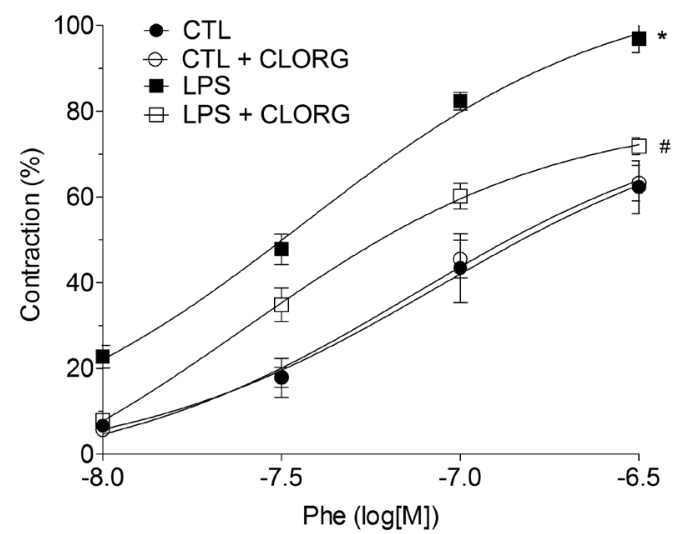

B

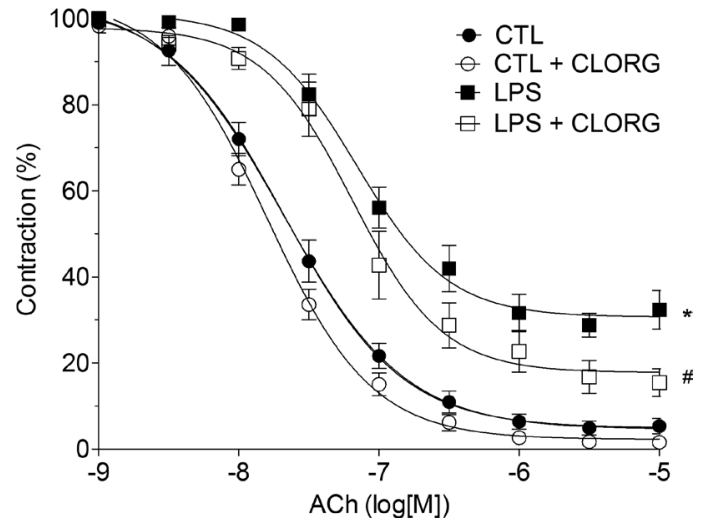

Figure 2. Effects of the irreversible MAO A inhibitor clorgyline (CLORG), on vascular reactivity in rat aortic rings after LPS treatment. A. Phenylephrine-induced contractions in aortic rings segments isolated from rats treated with lipopolysaccharide (LPS) or not (CTL) in the presence $v s$. absence CLORG $(10 \mu \mathrm{mol} / \mathrm{l})$. B. Acetylcholine-induced relaxation in aortic rings segments isolated from rats treated with lipopolysaccharide (LPS) or not (CTL) in the presence vs. absence of CLORG $(10 \mu \mathrm{mol} / \mathrm{l}) . n=6,{ }^{*} p<0.05$ LPS vs. CTL, \# $p<0.05$ vs. without CLRG.

significantly decreased $\mathrm{H}_{2} \mathrm{O}_{2}$ generation in the diseased vascular samples (Fig. 4).

\section{Discussion}

The purpose of this study was to assess the contribution of MAO to the development of endothelial dysfunction elicited by the in vivo administration of a single dose of LPS in rats. The major findings of this paper are as follows: i) both $\mathrm{MAO}$ isoforms are expressed in rat aortic rings with the predominance of the MAO-B isoform, at variance from the data found in mice where MAO-A was the predominant vascular isoform (Sturza et al. 2013a), ii) the upregulation of both MAO isoforms occurs after the LPS treatment, and iii) MAO inhibition is associated with the improvement of vascular function and mitigation of oxidative stress; these results are in line with the ones previously reported in the mice model of endothelial dysfunction (Sturza et al. 2013a).

Although inflammation is a condition clearly associated with oxidative stress and endothelial dysfunction, information about MAO in the setting of inflammation is scarce. Accordingly, in an experimental model of rat periodontitis elicited by the administration of LPS to the right and left gingival sulcus, at 5.72 -fold increase in the MAO-B gene expression was found in treated $v$ s. the non-treated group. After treatment with phenelzine (a non-selective, irreversible MAO inhibitor), $\mathrm{H}_{2} \mathrm{O}_{2}$ generation was significantly reduced (Ekuni et al. 2009).

Another experimental setting associated with inflammation is the ischemia/reperfusion (I/R) injury of the heart.

\section{A}

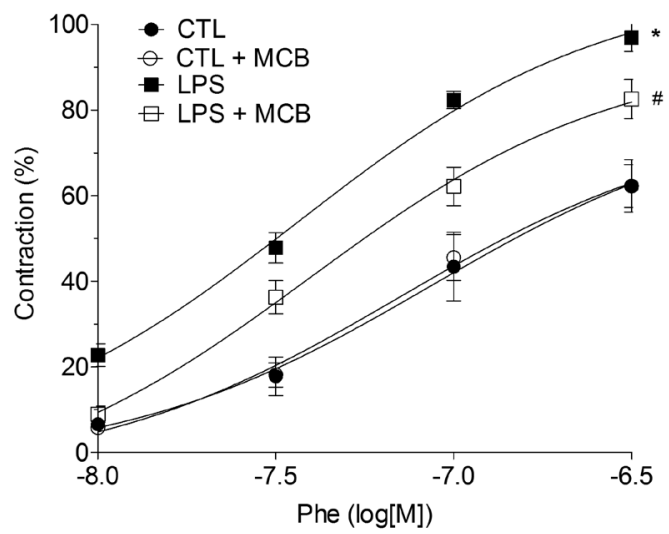

B

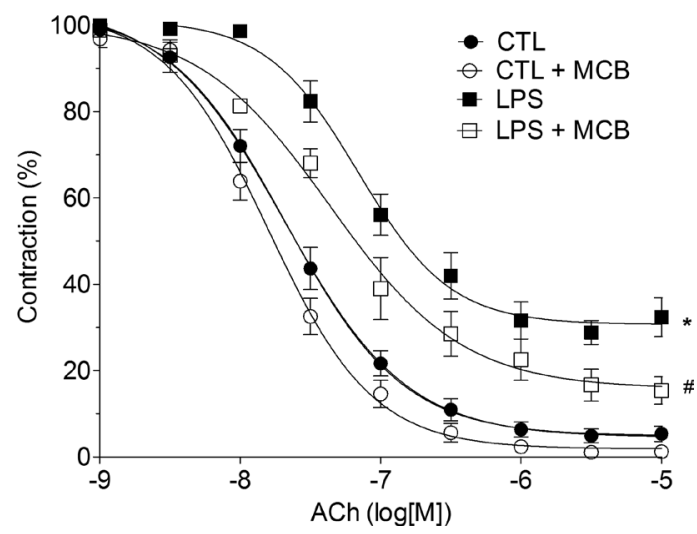

Figure 3. Effects of the irreversible MAO A inhibitor moclobemide (MCB) on vascular reactivity in rat aortic rings after lipopolysaccharide (LPS) treatment. A. Phenylephrine induced contractions in aortic rings segments isolated from rats treated with lipopolysaccharide (LPS) or not (CTL) in the presence $v s$. absence of MCB $(10 \mu \mathrm{mol} / \mathrm{l})$. B. Acetylcholine induced relaxation in aortic rings segments isolated from rats treated with LPS or not (CTL) in the presence $v s$. absence of MCB $(10 \mu \mathrm{mol} / \mathrm{l}) . n=6,{ }^{\star} p<0.05$ LPS $v s$. CTL, \# $p<0.05$ vs. without MCB. 
Vuohelainen et al. (2015) performed a study in Fischer rats where they induced reversible I/ $\mathrm{R}$ in the setting of the cardiac arrest elicited by heterotopic transplantation. Half of the rats additionally received a permanent ligation of the left anterior descending coronary artery to induce myocardial infarction (MI). Subcutaneous MCB $10 \mathrm{mg} / \mathrm{kg} /$ day was then given to rats with or without MI. In hearts exposed to IR injury and MI, MCB attenuated adventitial inflammation and progression of the intimal thickness of intra-myocardial arteries (Vuohelainen et al. 2015). Of note, MCB is the only reversible, devoid of the feared 'cheese effect' MAO-A inhibitor that is currently in the clinical use (Finberg and Rabey 2016).

MAOs have been extensively studied in the past century for their involvement in pathogenesis of neurodegenerative and psychiatric diseases (Yamada and Yasuhara 2004). In

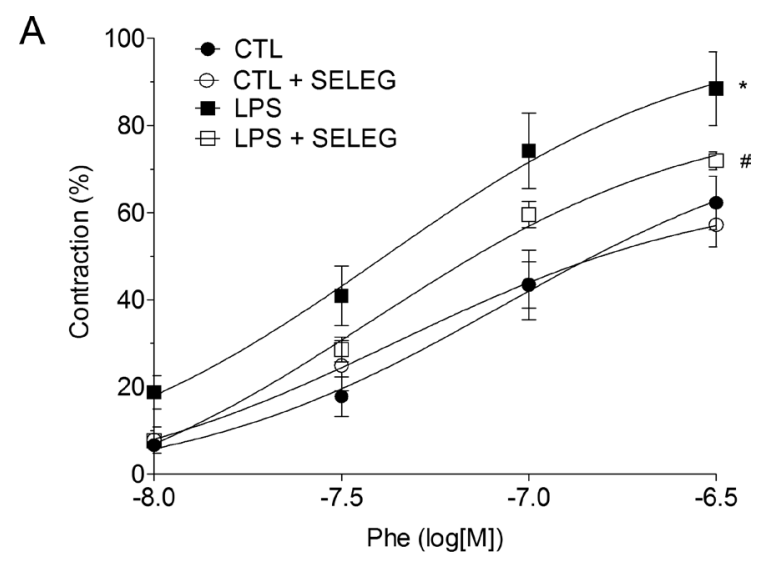

B

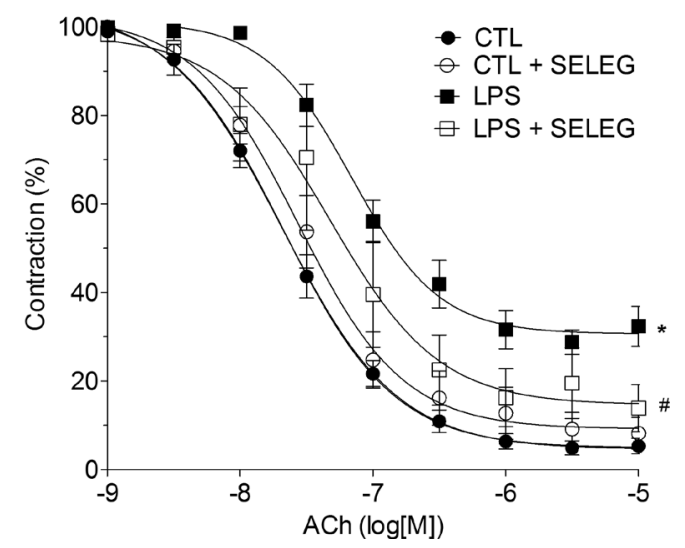

Figure 4. Effects of the irreversible MAO B inhibitor selegiline (SELEG) on vascular reactivity in rat aortic rings after lipopolysaccharide (LPS) treatment. A. Phenylephrine induced contractions in aortic rings segments isolated from rats treated with LPS or not $(\mathrm{CTL})$ in the presence $v$ s. absence of SELEG $(10 \mu \mathrm{mol} / \mathrm{l})$. B. Acetylcholine induced relaxation in aortic rings segments isolated from rats treated with LPS or not (CTL) in the presence $v s$. absence of SELEG $(10 \mu \mathrm{mol} / \mathrm{l}) . n=6,{ }^{*} p<0.05$ LPS $v$. CTL, $\# p<0.05$ vs. without SELEG.

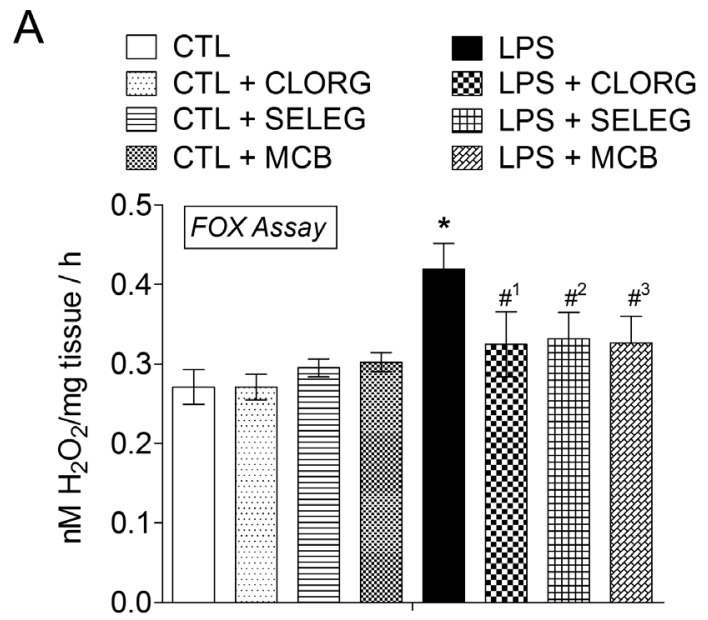

B

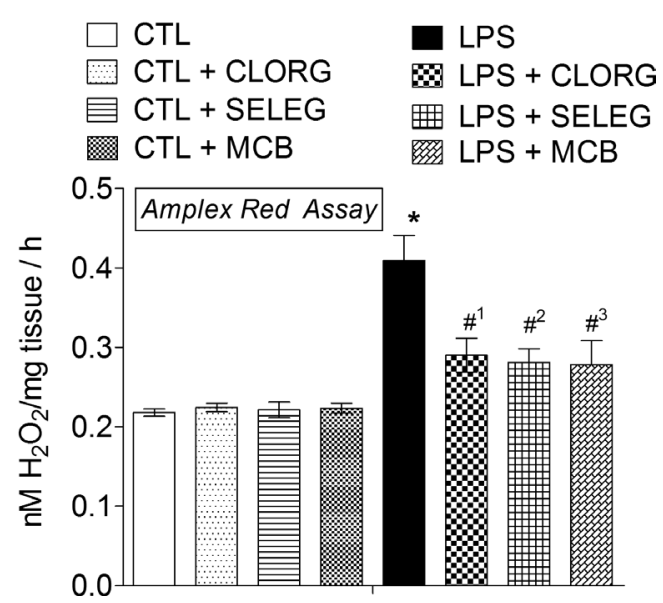

Figure 5. Effect of MAO inhibitors clorgyline, selegiline and moclobemide on aortic $\mathrm{H}_{2} \mathrm{O}_{2}$ generation after LPS treatment in rats. A. Aortic $\mathrm{H}_{2} \mathrm{O}_{2}$ formation measured by FOX assay. B. Aortic $\mathrm{H}_{2} \mathrm{O}_{2}$ formation measured by Amplex Red assay; $n=6$, ${ }^{*} p<0.05$ LPS vs. CTL, ${ }^{\#} p<0.05$ LPS+MAO inhibitors (CLORG $10 \mu \mathrm{mol} / \mathrm{l}$; SELEG $10 \mu \mathrm{mol} / \mathrm{l}$; MCB $10 \mu \mathrm{mol} / \mathrm{l}) v s$. LPS. For abbreviations, see Fig. 4.

this regard, a wide range of MAO inhibitors (MAOIs) are available and proven to have therapeutic value in several pathologies, including affective disorders, neurodegenerative diseases, stroke and senescence (Carradori and Petzer 2014). Currently, MAOIs are not the most widely prescribed antidepressants, being surpassed by the selective serotonin reuptake inhibitors or tricyclic antidepressants (which are also used in the treatment of diabetic neuropathy) (Griebeler et al. 2014). However, they remain an important therapeutic line in neurodegenerative diseases being also investigated for MAO-independent neuroprotective properties (Al-Nuaimi et al. 2012; Song et al. 2013). 
In the past decades, MAOs have emerged as key contributors to the pathogenesis of cardiovascular pathologies. Accordingly, the group of Prof. Di Lisa unequivocally demonstrated that upregulation/increased activity of MAO elicited both mitochondrial injury (Kaludercic et al. 2014b), and evolution of compensated cardiac hypertrophy to dilation and heart failure in the rodent heart (Kaludercic et al. 2010).

We have also evidentiated the ability of MAO inhibitors to decrease oxidative stress in various human and animal pathologies, namely in mammary artery and atrial samples isolated form diabetic and non-diabetic patients subjected for coronary artery by-pass surgery (Duicu et al. 2016; Lighezan et al. 2016), in patients with chronic kidney disease requiring hemodialysis (Utu et al. 2017), in aortic rings isolated from diabetic rats (Sturza et al. 2015), in dogs coronary arteries after angiotensin II stimulation (Sturza et al. 2015). In another study, ex vivo pretreatment with MAOIs attenuated the endothelial dysfunction in aortas from spontaneously hypertensive rats (Sturza et al. 2013). Similar results were obtained in basilar arteries obtained from hypertensive rats in which contractility was significantly reduced by MAOIs (Poon et al. 2010). Interestingly, treatment with angiotensin II converting enzyme inhibitors reduced MAO activity, suggesting the fact that activation of the renin-angiotensinaldosterone system is responsible for the increase in MAO activity (Raasch et al. 2002).

In the present model the amount of $\mathrm{H}_{2} \mathrm{O}_{2}$ production in aortic samples isolated from LPS-treated rats was 2 times higher than in controls while the ex vivo treatment with MAOI reduced by $50 \%$ the amount of $\mathrm{H}_{2} \mathrm{O}_{2}$ in the diseased samples. It is important to emphasize that $\mathrm{MAO}$ we have previously demonstrated that MAOIs had no effect on xanthine oxidase and NADPH oxidases-dependent $\mathrm{H}_{2} \mathrm{O}_{2}$ formation and do not act as $\mathrm{H}_{2} \mathrm{O}_{2}$ scavengers (Sturza et al. 2013). Another important observation is that MAOIs did not impact on $\mathrm{H}_{2} \mathrm{O}_{2}$ measurements and vascular reactivity of control samples. These findings strongly suggest that the reduction in $\mathrm{H}_{2} \mathrm{O}_{2}$ generation after pre-treatment with $\mathrm{MAOI}$ is a consequence of $\mathrm{MAO}$ inhibition and not of the pleiotropic effects of the drugs.

We also report the upregulation of MAO-B isoform in LPS-treated animals, an observation that requires further mechanistic dissection.

The limitations of the present study are that we performed the functional analysis in isolated vessels and did not used genetic manipulation.

In summary, we demonstrated that MAOs play a role in the vascular impairment in the setting of systemic inflammation induced by LPS in rat. MAO contribution to the endothelial activation and dysfunction in cardiometabolic conditions associated with low-grade inflammation as well as the assessment of the therapeutic role of the clinically available (reversible) MAO inhibitors are clearly warranted.

\section{Conclusion}

In the present study we identified MAOs as novel mediators of endothelial dysfunction associated with the LPS-related acute inflammation in the rat. MAO inhibition might be useful to alleviate vascular dysfunction in conditions associated with inflammation and oxidative stress.

Conflicts of interest: The authors declare no conflicts of interest.

Acknowledgement. Research supported by the university grant PIII-C5-PCFI-2017/2018-01. Danina M. Muntean and Adrian Sturza are members of the European Cooperation in Science and Technology (COST) Action CA16225 EU-CARDIOPROTECTION.

\section{References}

Al-Nuaimi SK, Mackenzie EM, Baker GB (2012): Monoamine oxidase inhibitors and neuroprotection: a review. Am. J. Ther. 19, 436-448 https://doi.org/10.1097/MJT.0b013e31825b9eb5

Bortolato M, Chen K, Shih JC (2008): Monoamine oxidase inactivation: from pathophysiology to therapeutics. Adv. Drug Deliv. Rev. 60, 1527-1533 https://doi.org/10.1016/j.addr.2008.06.002

Brandes RP, Weissmann N, Schroder K (2010): NADPH oxidases in cardiovascular disease. Free Radic. Biol. Med. 49, 687-706 https://doi.org/10.1016/j.freeradbiomed.2010.04.030

Carradori S, Petzer JP (2014): Novel monoamine oxidase inhibitors: a patent review $(2012-2014)$. Expert Opin. Ther. Pat. 1-20

Daiber A, Munzel T (2015): Organic nitrate therapy, nitrate tolerance, and nitrate-induced endothelial dysfunction: emphasis on redox biology and oxidative stress. Antioxid. Redox Signal. 23, 899-942 https://doi.org/10.1089/ars.2015.6376

Drose S, Brandt U (2012): Molecular mechanisms of superoxide production by the mitochondrial respiratory chain. Adv. Exp. Med. Biol. 748, 145-169 https://doi.org/10.1007/978-1-4614-3573-0_6

Duicu OM, Lighezan R, Sturza A, Ceausu RA, Borza C, Vaduva A, Noveanu L, Gaspar M, Ionac A, Feier H, et al. (2015): Monoamine oxidases as potential contributors to oxidative stress in diabetes: Time for a study in patients undergoing heart surgery. Biomed. Res. Int. 2015, 515437 https://doi.org/10.1155/2015/515437

Duicu OM, Lighezan R, Sturza A, Balica R, Vaduva A, Feier H, Gaspar M, Ionac A, Noveanu L, Borza C, et al. (2016): Assessment of mitochondrial dysfunction and monoamine oxidase contribution to oxidative stress in human diabetic hearts. Oxid. Med. Cell. Longev. 2016, 8470394 https://doi.org/10.1155/2016/8470394

Edmondson DE, Binda C (2018): Monoamine oxidases. Subcell. Biochem. 87, 117-139 https://doi.org/10.1007/978-981-10-7757-9_5

Ekuni D, Firth JD, Nayer T, Tomofuji T, Sanbe T, Irie K, Yamamoto T, Oka T, Liu Z, Vielkind J, Putnins EE (2009): Lipopolysaccha- 
ride-induced epithelial monoamine oxidase mediates alveolar bone loss in a rat chronic wound model. Am. J. Pathol. 175, 1398-1409 https://doi.org/10.2353/ajpath.2009.090108

Finberg JP, Rabey JM (2016): Inhibitors of MAO-A and MAO-B in psychiatry and neurology. Front. Pharmacol. 7, 340 https://doi.org/10.3389/fphar.2016.00340

Forstermann U, Sessa WC (2012): Nitric oxide synthases: regulation and function. Eur. Heart J. 33, 829-837 https://doi.org/10.1093/eurheartj/ehr304

Galley JC, Straub AC (2017): Redox control of vascular function. Arterioscler. Thromb. Vasc. Biol. 37, e178-184 https://doi.org/10.1161/ATVBAHA.117.309945

Griebeler ML, Morey-Vargas OL, Brito JP, Tsapas A, Wang Z, Carranza Leon BG, Phung OJ, Montori VM, Murad MH (2014): Pharmacologic interventions for painful diabetic neuropathy: an umbrella systematic review and comparative effectiveness network meta-analysis. Ann. Intern. Med. 161, 639-649 https://doi.org/10.7326/M14-0511

Grimsby J, Lan NC, Neve R, Chen K, Shih JC (1990): Tissue distribution of human monoamine oxidase $\mathrm{A}$ and $\mathrm{B}$ mRNA. J. Neurochem. 55, 1166-1169 https://doi.org/10.1111/j.1471-4159.1990.tb03121.x

Higgins P, Dawson J, Lees KR, McArthur K, Quinn TJ, Walters MR (2012): Xanthine oxidase inhibition for the treatment of cardiovascular disease: a systematic review and meta-analysis. Cardiovasc. Ther. 30, 217-226 https://doi.org/10.1111/j.1755-5922.2011.00277.x

Kaludercic N, Takimoto E, Nagayama T, Feng N, Lai EW, Bedja D, Chen K, Gabrielson KL, Blakely RD, Shih JC, et al. (2010): Monoamine oxidase A-mediated enhanced catabolism of norepinephrine contributes to adverse remodeling and pump failure in hearts with pressure overload. Circ. Res. 106, 193-202 https://doi.org/10.1161/CIRCRESAHA.109.198366

Kaludercic N, Carpi A, Nagayama T, Sivakumaran V, Zhu G, Lai EW, Bedja D, De Mario A, Chen K, Gabrielson KL, et al. (2014a): Monoamine oxidase B prompts mitochondrial and cardiac dysfunction in pressure overloaded hearts. Antioxid. Redox. Signal. 20, 267-280 https://doi.org/10.1089/ars.2012.4616

Kaludercic N, Mialet-Perez NJ, Paolocci N, Parini A, Di Lisa F (2014b): Monoamine oxidases as sources of oxidants in the heart. J. Mol. Cell. Cardiol. 73, 34-42 https://doi.org/10.1016/j.yjmcc.2013.12.032

Lighezan R, Sturza A, Duicu OM, Ceausu RA, Vaduva A, Gaspar M, Feier H, Vaida M, Ivan V, Lighezan D, et al. (2016): Monoamine oxidase inhibition improves vascular function in mammary arteries from nondiabetic and diabetic patients with coronary heart disease. Can. J. Physiol. Pharmacol. 94, 1040-1047 https://doi.org/10.1139/cjpp-2015-0580

Maggiorani D, Manzella N, Edmondson DE, Mattevi A, Parini A, Binda C, Mialet-Perez J (2017): Monoamine oxidases, oxidative stress, and altered mitochondrial dynamics in cardiac ageing. Oxid. Med. Cell. Longev. 2017, 3017947 https://doi.org/10.1155/2017/3017947

Mozos I, Luca CT (2017): Crosstalk between oxidative and nitrosative stress and arterial stiffness. Dis. Markers 15, 446-456
Mozos I, Stoian D (2017): Crosstalk between vitamins A, B12, $\mathrm{D}, \mathrm{K}, \mathrm{C}$, and E status and arterial stiffness. Dis. Markers 2017, 8784971 https://doi.org/10.1155/2017/8784971

Muntean DM, Sturza A, Danila MD, Borza C, Duicu OM, Mornos C (2016): The role of mitochondrial reactive oxygen species in cardiovascular injury and protective strategies. Oxid. Med. Cell. Longev. 2016, 8254942 https://doi.org/10.1155/2016/8254942

Poon CC, Seto SW, Au AL, Zhang Q, Li RW, Lee WY, Leung GP, Kong SK, Yeung JH, Ngai SM, et al. (2010): Mitochondrial monoamine oxidase-A-mediated hydrogen peroxide generation enhances 5-hydroxytryptamine-induced contraction of rat basilar artery. Br. J. Pharmacol. 161, 1086-1098 https://doi.org/10.1111/j.1476-5381.2010.00941.x

Raasch W, Bartels T, Gieselberg A, Dendorfer A, Dominiak P (2002): Angiotensin I-converting enzyme inhibition increases cardiac catecholamine content and reduces monoamine oxidase activity via an angiotensin type 1 receptor-mediated mechanism. J. Pharmacol. Exp. Ther. 300, 428-434 https://doi.org/10.1124/jpet.300.2.428

Song MS, Matveychuk D, MacKenzie EM, Duchcherer M, Mousseau DD, Baker GB (2013): An update on amine oxidase inhibitors: multifaceted drugs. Prog. Neuropsychopharmacol. Biol. Psychiatry 44,118-124

https://doi.org/10.1016/j.pnpbp.2013.02.001

Sturza A, Duicu OM, Vaduva A, Danila MD, Noveanu L, Varro A, Muntean DM (2015a): Monoamine oxidases are novel sources of cardiovascular oxidative stress in experimental diabetes. Can. J. Physiol. Pharmacol. 93, 555-561 https://doi.org/10.1139/cjpp-2014-0544

Sturza A, Leisegang MS, Babelova A, Schroder K, Benkhoff S, Loot AE, Fleming I, Schulz R, Muntean DM, Brandes RP (2013a): Monoamine oxidases are mediators of endothelial dysfunction in the mouse aorta. Hypertension 62, 140-146 https://doi.org/10.1161/HYPERTENSIONAHA.113.01314

Sturza A, Mirica SN, Duicu O, Gheorgheosu D, Noveanu L, FiraMladinescu O, Muntean DM (2013b): Monoamine oxidase-A inhibition reverses endothelial dysfunction in hypertensive rat aortic rings. Rev. Med. Chir. Soc. Med. Nat. Iasi. 117, 165-171

Sturza A, Noveanu L, Duicu O, Danila M, Jost N, Muntean D, Munteanu M (2015b): Reversible inhibition of monoamine oxidase - a improves vascular dysfunction in canine carotid arteries exposed to angiotensin II. Rev. Chim. 66, 851-854

Tripathi AC, Upadhyay S, Paliwal S, Saraf SK (2018): Privileged scaffolds as MAO inhibitors: Retrospect and prospects. Eur. J. Med. Chem. 145, 445-497 https://doi.org/10.1016/j.ejmech.2018.01.003

Utu D, Pantea S, Duicu OM, Muntean D, Sturza A (2017): Contribution of monoamine oxidases to vascular oxidative stress in patients with end-stage renal disease requiring hemodialysis. Can. J. Physiol. Pharmacol. 95, 1383-1388 https://doi.org/10.1139/cjpp-2017-0067

Vuohelainen V, Hamalainen M, Paavonen T, Karlsson S, Moilanen E, Mennander A (2015): Inhibition of monoamine oxidase A increases recovery after experimental cardiac arrest. Interact. Cardiovasc. Thorac. Surg. 21, 441-449 https://doi.org/10.1093/icvts/ivv175 
Westlund KN, Krakower TJ, Kwan SW, Abell CW (1993): Intracellular distribution of monoamine oxidase A in selected regions of rat and monkey brain and spinal cord. Brain Res. 612, 221-230.

https://doi.org/10.1016/0006-8993(93)91664-E

Yamada M, Yasuhara H (2004): Clinical pharmacology of MAO inhibitors: safety and future. Neurotoxicology 25, 215-221 https://doi.org/10.1016/S0161-813X(03)00097-4
Youdim MB, Edmondson D, Tipton KF (2006): The therapeutic potential of monoamine oxidase inhibitors. Nat. Rev. Neurosci. 7, 295-309

https://doi.org/10.1038/nrn1883

Received: December 17, 2017

Final version accepted: April 19, 2018

First published online: July 31, 2018 